\title{
Infezioni virali nel trapiantato renale
}

\author{
G.Quintaliani', R.Brugnano' ${ }^{1}$, D.Francisci ${ }^{2}$, U.Buoncristiani ${ }^{1}$ \\ ${ }^{1}$ U.O.Nefrologia, Ospedale Silvestrini, Perugia \\ ${ }^{2}$ Istituto Malattie Infettive, Università degli Studi, Perugia
}

infezione rimane, a tutt'oggi, la principale causa di morbilità e mortalità nel portatore di trapianto renale. La necessità di una immunosoppressione permanente, l'eventuale ricorso a supplementi di terapia immunosoppressiva per il trattamento del rigetto, l'effetto immunomodulatore di alcuni virus, il quadro clinico non sempre suggestivo di infezione, le difficoltà associate al trattamento spiegano l'importanza della prevenzione e della diagnosi precoce dei processi infettivi nel trapiantato renale. Gli agenti responsabili delle infezioni variano notevolmente con il periodo del trapianto e lo schema temporale (Fig 1) sviluppato da Rubin e coll. può essere molto utile nel valutare il paziente trapiantato febbrile.

Nel I mese post-trapianto, la maggior parte delle infezioni è legata alla procedura chirurgica o alla emergenza di una infezione non eradicata prima del trapianto. Dal I al VI mese post-trapianto le più importanti cause di infezione sono i virus ed i classici patogeni opportunistici quali la Pneumocystis carinii, la $\mathrm{Li}$ steria monocytogenes, l'Aspergillus fumigatus. Dopo il VI mese il soggetto trapiantato rimane a rischio delle comuni infezioni presenti nella popolazione generale (influenza, polmonite pneumococcica, infezioni vie urinarie) e, quelli con storia di rigetto acuto e cronico, a causa della maggiore immunosoppres- sione, a maggior rischio di infezioni opportunistiche.

Le infezioni virali rappresentano una delle principali cause di morbilità nel trapiantato renale sia ad opera di virus comunemente presenti nella popolazione come i mixovirus, paramixovirus e picornavirus (responsabili di infezioni acute ad evoluzione benigna), sia ad opera di virus come gli Herpes virus, i virus epatitici, i retrovirus responsabili di infezioni ad evoluzione cronica o prolungata. In particolare la famiglia degli Herpes virus (Cytomegalovirus, Epstein-Barr virus, Varicella-zoster, Herpes virus simplex 1, Herpes virus simplex $2 \mathrm{e}$ Herpes virus umano 6 ) risulta temibile per le caratteristiche di latenza (capacità del virus di persistere allo stato latente nell'ospite infettato e di riattivarsi anche dopo lungo tempo), di potenziale oncogenicità e di interferenza con le difese immunologiche dell'ospite. Un indicatore laboratoristico della presenza di virus latenti e della eventuale immunizzazione è la presenza di anticorpi circolanti ("sieropositività").

Il Cytomegalovirus (CMV) è il più importante agente virale responsabile di infezione nel trapiantato renale; circa il $60-70 \%$ dei pazienti trapiantati ha evidenza di infezione citomegalica nonostante la malattia clinicamente sia presente in un minor numero. Difatti, mentre nella popolazione normale il CMV non produce sintomi, nel soggetto trapianta to l'infezione è spesso sintomatica e severa. L'infezione può essere primaria quando le cellule infette sono trasmesse ad un ricevente sieronegativo tramite l'organo trapiantato o emoderivati; l'infezione secondaria si verifica, invece, nel paziente già sieropositivo o per riattivazione di un virus endogeno latente o per superinfezione da parte del virus presente nell'organo trapiantato. La severità della infezione è maggiore nel caso di infezione primaria ma in entrambe le situazioni è direttamente correlata al grado di immunosoppressione del paziente; inoltre anche la strategia terapeutica immunosoppressiva sembra avere un ruolo nel determinare una diversa incidenza di infezioni essendosi rilevata una maggiore ricorrenza infettiva in pazienti trattati con preparazioni di anticorpi anti-linfocitari.

Circa il 35\% dei pazienti trapiantati manifesta nel I anno post-trapianto una malattia conclamata e circa il $2 \%$ muore in seguito alle complicanze correlate all'infezione (CL Davis: Am J Kidney Dis. 1990; 16: 175; Snyaman DR, Werner BG, Tilney NL et al. Transplant Proc. 1991; 23: 1357). I sintomi suggestivi di infezione sono la febbre continua o intermittente, il malessere, l'astenia, meno frequentemente artralgie, splenomegalia, mialgie, dolori addominali, nausea e vomito. Spesso alle indagini di la- 


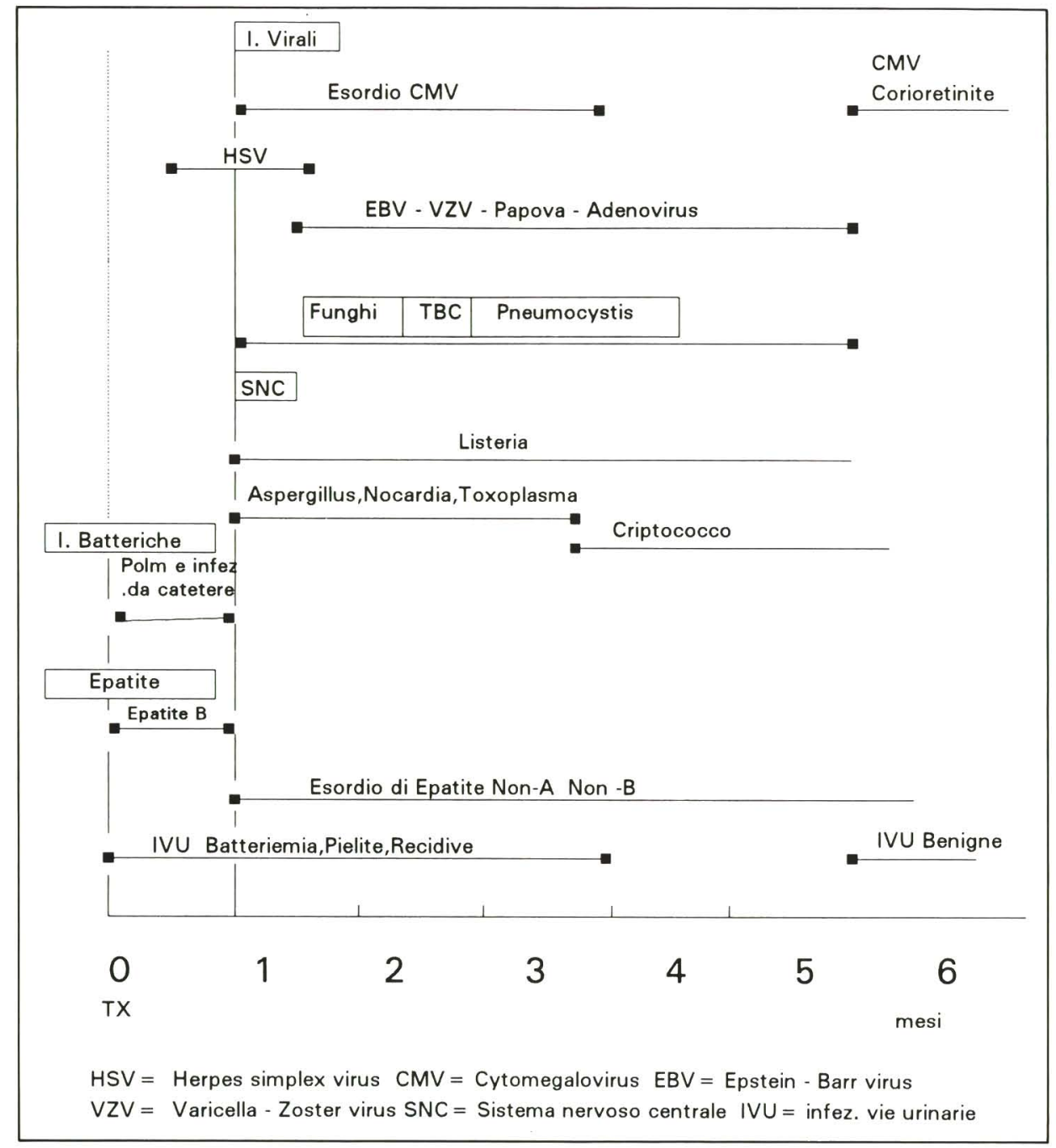

Fig. 1 - Sequenza temporale delle infezioni nel trapianto renale. (Da Rubin et al 1991).

boratorio è presente leucopenia con neutropenia, piastrinopenia; più raramente aumento dei livelli delle transaminasi o anemia per emorragie gastrointestinali. Circa due terzi dei pazienti manifesta sintomi respiratori con dispnea ed ipossiemia con un quadro radiologico di interstiziopatia bilaterale ma la progressione verso il distress respiratorio è in genere legata a concomitanti infezioni fungine o da Pneumocystis carinii. Una precoce diagnosi di laboratorio è auspicabile ma spesso difficile:la comparsa di IgM specifiche anti-CMV pur essendo diagnostica si verifica in genere da 1 a 6 giorni dall'esordio dei sintomi e l'aumento di almeno 4 volte, del titolo delle $\mathrm{IgG}$ può essere ancora più tardivo. La diagnosi si basa sull'isolamento del virus su colture di fibroblasti embrionali uma- ni utilizzando campioni di urine, saliva, sangue (frazione leucocitaria) ma la comparsa dell' effetto citopatico richiede da 5 a 28 giorni e questo non permette una diagnosi precoce. Recentemente più rapidi metodi di indagine sono stati attuati con tecniche di identificazione del DNA del CMV con ibridizzazione (sonde a DNA) o con l'identificazione di antigeni virali precoci (mediante immunofluorescenza con anticorpi monoclonali) prodotti su colture virali entro 24 ore. Le infezioni di media gravità non richiedono un trattamento specifico mentre le infezioni conclamate rispondono al trattamento con ganciclovir (5 $\mathrm{mg} / \mathrm{kg}$ due volte al giorno per 2-3 settimane) eventualmente associa to a immunoglobuline iperimmuni anti-CMV. Naturalmente la prevenzione rimane l'obiettivo ideale in considerazione anche del ruolo svolto dalla infezione da CMV sul decorso del trapianto renale, in particolare sulla maggiore frequenza di episodi di rigetto legata alla omologia tra alcuni antigeni del CMV ed alcuni antigeni di istocompatibilità o all'effetto immunomodulatore svolto dallo stesso virus.

Un altro virus della famiglia degli Herpes, il virus di Epstein-Barr (EBV) risulta essere responsabile di vari quadri clinici nel trapiantato renale; la sua reale frequenza non è ancora chiara a causa della similarità con le infezioni da $\mathrm{CMV}$ e della difficoltà diagnostica. Circa i due terzi dei soggetti trapiantati eliminano con le secrezioni faringee l'EBV. La riattivazione del virus latente è legata nel trapiantato alla immunosoppressione. Difatti nella infezione naturale dopo la replicazione del virus nel tratto orofaringeo si verifica l'infezione secondaria dei linfociti B che, nell'individuo normale, vengono distrutti dalle cellule T citotossiche; nel soggetto trapiantato, per effetto della terapia immunosoppressiva, questo meccanismo non si attiva. I quadri clinici della infezione da EBV possono essere sostanzialmente di due tipi (Fig 2): un quadro simile alla infezione da CMV con febbre, epatite, linfoadenopatia, linfocitosi atipica, leucopenia e trombocitopenia ed un quadro legato alla capacità oncogenetica del virus manifestantesi con malattie linfoproliferative (linfoma maligno del sistema nervoso centrale, del tratto gastrointestinale, dell'orofaringe e spesso a sede extralinfonodale). La diagnosi si fonda su criteri essenzialmente sierologici non essendo possibile routinariamente isolare il virus da campioni biologici; nel soggetto immunodepresso, d'altra parte, $i$ criteri sierologici non sono affidabili perchè la immunodepressione maschera la risposta anticorpale.

L'infezione primaria da virus VaricellaZoster (VZV) si può verificare nel trapiantato renale in qualsiasi momento del post-trapianto e può avere sequele disastrose con un interessamento viscerale disseminato, una polmonite, una encefalite o meningite, una coagulazione intravascolare disseminata ed esitare nella morte. L'avvio precoce di una terapia con acyclovir intravenoso ad alte dosi può risultare efficace. Tuttavia, vista la gravità che può assumere la malat- 


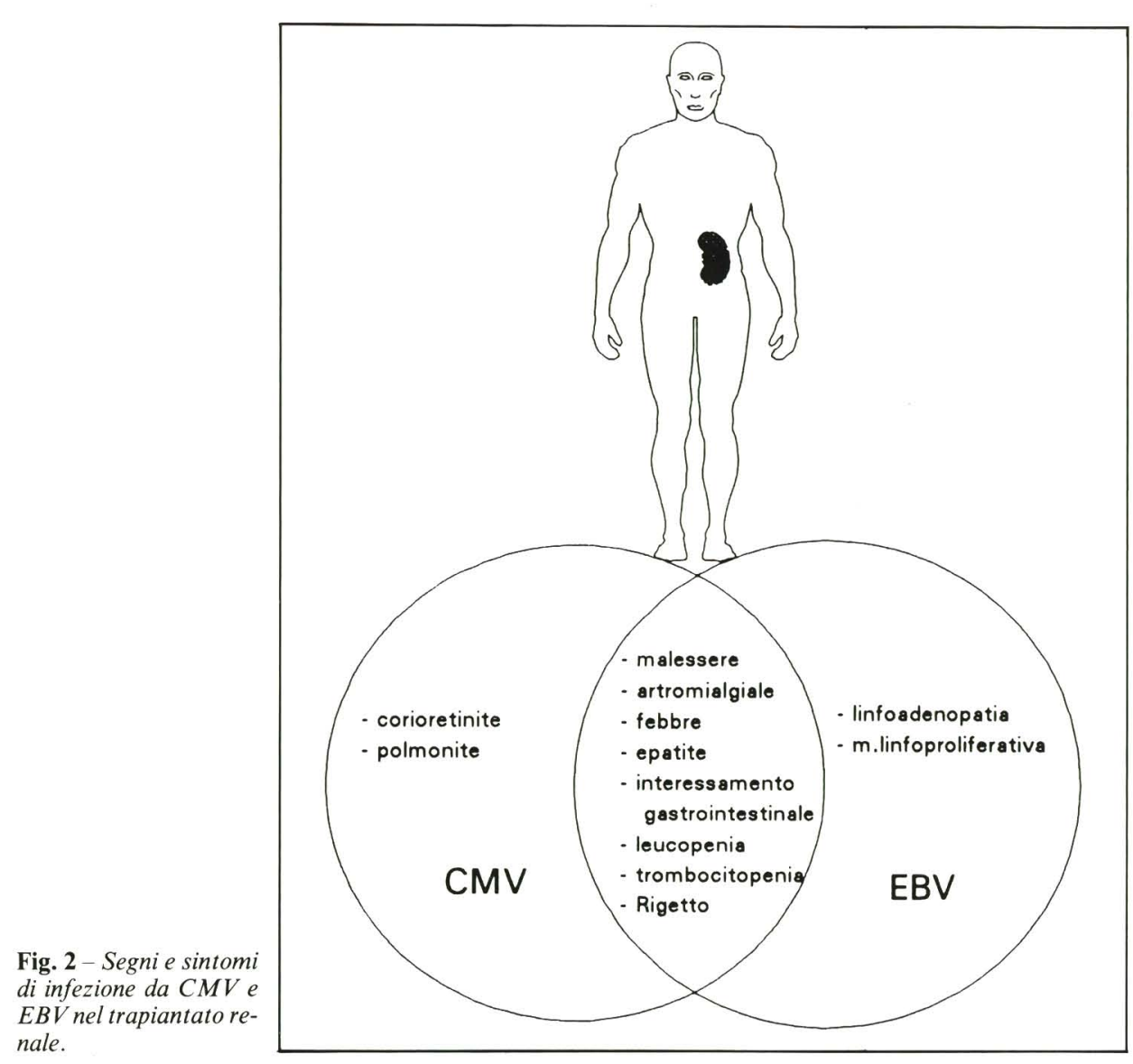

tia, rimane fondamentale lo screening dei candidati al trapianto: i soggetti sieronegativi a rischio di infezione primaria devono essere sottoposti a vaccinazione ed i soggetti sieropositivi, in caso di esposizione ambientale al virus, dovrebbero ricevere una immunizzazione passiva mediante immunoglobuline specifiche. In contrasto con la gravità delle infezioni primarie, la riattivazione del VZV con un tipico quadro di zoster interessante 2 o 3 dermatomeri, interessa il $20-30 \%$ dei trapiantati ed ha un quadro a decorso benigno.

Circa il 10-15\% dei soggetti trapiantati renali manifesta una malattia epatica cronica; la principale causa di tale malattia rimane l'infezione da virus epatite $B(\mathrm{HBV})$ e da virus epatite $C$ ( $\mathrm{HCV}$ ). L'infezione primaria è acquisita al momento del trapianto da un organo infetto; si tratta di una evenienza estremamente rara per l'HBV, grazie agli attuali metodi di screening degli antigeni di superficie del virus mentre non si può dire lo stesso per l'HCV. Nel caso di infezione primaria il decorso può essere quello di una epatite fulminante $o$, più frequen- temente, di una disfunzione epatocellulare lenta che appare da 1 a 4 mesi posttrapianto e decorre per tutta la vita. Più complesso il problema del paziente candidato a trapianto renale, portatore cronico dell'HBV; in questo caso la terapia immunosoppressiva può incrementare la replicazione virale con un andamento evolutivo della malattia epatica ed un ulteriore rischio oncogeno. Purtroppo in questi casi anche la terapia con alfainterferon è risultata inefficace; pertanto lo stato di portatore cronico di HBV può essere un fattore di rischio aggiuntivo alla procedura del trapianto, necessitante una attenta valutazione della istologia epatica, del grado di replicazione virale, delle condizioni generali. Per quanto riguarda l'HCV l'espressione clinica della infezione nel trapiantato è quella di una malattia epatica lentamente progressiva; anche in questo caso non è disponibile una efficace terapia. Attualmente, peraltro, molti sono i progressi nella identificazione dello stato di infezione del paziente e della trasmissibilità della infezione virale.

In conclusione $i$ virus, in particolare il
CMV, l'EBV e i virus dell'epatite, possono determinare una svolta nella storia di un trapianto renale sia per la malattia infettiva stessa che per gli effetti immunomodulatori determinati.

Peraltro le strategie terapeutiche specifiche, soprattutto nel caso del CMV e dell'EBV sono evolute e divenute più efficaci mentre altrettanto non si può affermare nel caso delle epatiti dove è auspicabile che la ricerca possa quanto prima fornire opzioni e terapie sempre più valide.

\section{BIBLIOGRAFIA}

1 Morris RJ. Kidney Transplantation. Principles and practice. Kidney Int 1988,551-66.

2 Tolkoff Rubin NE, Rubin RH. Viral Infection in the renal transplant recipient. Current Opinion in Nephrology and Hypertension 1991; 1: 243-8.

3 Tolkoff Rubin NE, Rubin $\mathrm{RH}$. Clinical approach to viral and fungal infections in the renal transplant patient. Semin Nephrol 1992; 12: 364-75.

4 Rubin RH. Nephrology Forum: Infectious disease complications of renal transplantation 1993; 44: 221-36. 